\title{
Hysterical Visual Loss and Malingering - Diagnostic Dilemma for an Ophthalmologist
}

\author{
Deepak Kumar Sharmaㄹ, Pankaj Kumar Thakur², Anubhav Chauhan ${ }^{3}$, Anchit Wapa ${ }^{4}$, Gian Chand Rajput ${ }^{5}$ \\ 1, 2, 3, 4,5 Department of Ophthalmology, Shri Lal Bahadur Shastri Government Medical \\ College, Mandi at Ner Chowk, Himachal Pradesh, India.
}

\section{ABSTRACT}

\section{BACKGROUND}

Attenuation of vision may be due to underlying organic condition or due to functional visual disorder or malingering if secondary gain is associated. Causes of pathological vision loss include advanced primary open angle glaucoma, hereditary macular dystrophies and optic neuropathies. Problem in establishing diagnosis is faced where superimposition of organic and functional visual loss is there. Distinction between functional visual loss and pathological visual loss is made by thorough and careful examination of the patient by applying basic rules and tools of ophthalmology in which examining surgeon is well versed, but patient is unaware. During routine practice, every ophthalmologist encounters patients with nonorganic vision loss. The purpose of the article is to demonstrate how to distinguish between normal visual function without missing any organic visual loss. Examination of such patients requires number of tests including baseline visual acuity, pupillary reactions, slit lamp examination of anterior segment, fundus examination, visual field analysis, optical coherence tomography, visual evoked potential and electroretinography. By proving integrity and functioning of visual system, diagnosis of functional visual loss can be confirmed. Once the conclusive diagnosis is established, it is to be revealed with caution to the patient/patient's attendant as it can lead to medico legal issues. Here, we present series of cases who presented to us in a tertiary care center of North India during a period of six months in the year of 2019 where case 1 and case 2 presented with decreased vision due to underlying pathological condition, case 3 presented with reduced vision due to functional visual disorder. Case 4,5 and 6 provided decisive evidence of malingering.

\section{KEY WORDS}

Fogging, Hysterical Visual Loss, Malingering, Menace Reflex, Optokinetic Nystagmus.

\author{
Corresponding Author: \\ Dr. Deepak Kumar Sharma, \\ Department of Ophthalmology, \\ Shri Lal Bahadur Shastri \\ Government Medical College, \\ Mandi at Ner Chowk-175021, \\ Himachal Pradesh, India. \\ E-mail:drdksharma5@rediffmail.com
}

DOI: $10.14260 /$ jemds/2021/698

How to Cite This Article:

Sharma DK, Thakur PK, Chauhan A, et al. Hysterical visual loss and malingering diagnostic dilemma for an ophthalmologist. J Evolution Med Dent Sci 2021;10(38):3449-3453, DOI: 10.14260/jemds/2021/698

Submission 29-06-2021, Peer Review 24-08-2021, Acceptance 30-08-2021, Published 20-09-2021.

Copyright (C) 2021 Deepak Kumar Sharma et al. This is an open access article distributed under Creative Commons Attribution License [Attribution 4.0 International (CC BY 4.0)] 


\section{BACKGROUND}

In nonorganic vision loss (NOVL), no underlying pathology is detected either by clinical examination or by specialized tests. Meticulous history and careful examination of the patient is essential prerequisite to reach to the diagnosis. Physician has to be careful when NOVL is masked by some underlying neurological cause. Clinical tests must be performed with utmost care followed by investigations like computed tomography (CT) and magnetic resonance imaging (MRI) to demonstrate the integrity of visual system and confirm the diagnosis of NOVL.

\section{Case 1}

A 60 years old female patient was referred from psychiatry outpatient department (OPD) with complaints of decreased vision. She was on antipsychotic drugs for last four years for varied complaints like depression, visual hallucinations and impaired visual field. On examination, her visual acuity was $6 / 24$ both eyes with no improvement with glasses. In both eyes, intra ocular pressure (IOP) was $60 \mathrm{~mm}$ of $\mathrm{Hg}$ and complete cupping on fundus examination. Angle of anterior chamber was open in both eyes. Visual field analysis demonstrated advanced visual field defects in both eyes. Diagnosis of advanced open angle glaucoma was made and patient was put on anti-glaucoma medication.

\section{Case 2}

A 70-year-old male patient was referred from psychiatry OPD with complaints of decreased vision which was sudden in onset, painless and progressive in nature. The vision deteriorated to perception of light in both eyes within five days. Patient was taking treatment from the psychiatry department for altered behaviour and disorientation. Ocular examination revealed his visual acuity to behand movement close to face only with sluggish pupillary light reflex and normal near reflex. IOP was $16 \mathrm{~mm}$ of $\mathrm{Hg}$ in both eyes by Goldman applanation tonometer. Slit lamp examination (SLE) revealed normal anterior segment. Fundus examination revealed disc oedema in both eyes. Magnetic resonance imaging was done which revealed glioblastoma of brain. Patient was referred to the department of neurosurgery but unfortunately patient died after one week.

\section{Case 3}

A 26-year-old female patient visited eye OPD along with her husband and reported complete loss of vision in her eyes since last two days. Decreased vision was sudden in onset and painless. Attendant of the patient revealed that commencement of loss of vision was during the time when the patient was given the responsibility of looking after the shop which her husband was running. Examination revealed that there was no perception of light in both eyes. SLE of anterior segment was normal and no refractive error was detected. Pupillary reflexes were normal. IOP was $12 \mathrm{~mm}$ of $\mathrm{Hg}$ in both the eyes. Menace reflex was positive. Fundus examination was normal. Systemic examination was essentially normal. Fixation test was done by using 10 prism diopter base out prism, which showed refixation movement of the other eye. After complete evaluation, her visual acuity was found to be $6 / 6$ in both eyes. Diagnosis of functional visual loss was made, and patient was managed in consultation with department of psychiatry.

\section{Case 4}

A 65-year-old male presented himself before the disability board for disability certificate with decreased vision in his both eyes from last six months. Patient was referred to us for evaluation and find out the cause of vision loss. Preliminary examination revealed visual acuity $\mathrm{PL}+\mathrm{ve}$ in his right eye and 6/24 in his left eye. IOP was $12.0 \mathrm{~mm}$ of $\mathrm{Hg}$ in both eyes. There was no refractive error. SLE was normal and fundus examination revealed normal fundus. Fogging test was done by using $+10 \mathrm{D}$ lens in front of his left eye which revealed person could read better than $6 / 18$ by his right eye. Diagnosis of malingering was made and referred back to the board.

\section{Case 5}

A 35-year-old female patient with phthisis bulbi left eye was referred from other institution for evaluation to find out the cause of decreased vision in her right eye. She had appeared in that institution for disability certification. She was referred with visual acuity PL - ve in left eye and 6/24 in right eye. On examination, it was found that her left eye was phthisical and visual acuity was $6 / 24$ in her right eye without any refractive error. On SLE anterior segment of right eye was normal. IOP was $12 \mathrm{~mm}$ of $\mathrm{Hg}$ and fundus examination was normal. When her visual acuity was tested by decreasing the distance, patient read only up to $6 / 24$ line raising suspicion that she was telling lie.

\section{Case 6}

A 20-year-old male presented in eye OPD was referred from peripheral health institution for second opinion. The patient had appeared in the peripheral health institute for disability certificate. Patient was not carrying any previous health record except referral slip from the district medical board for second opinion. On his referral slip, his visual acuity was reported to be $6 / 60$ in right eye and 6/24 in left eye. On examination, patient read topmost line of Snellen's visual acuity chart by his right eye and up to third line with his right eye from a distance of six meters. When examination was performed from a varying distance of $5 \mathrm{~m}, 4 \mathrm{~m}, 3 \mathrm{~m}, 2 \mathrm{~m}$ and $1 \mathrm{~m}$, his visual acuity was again noticed to be $6 / 60$ and $6 / 24$ only. There was no refractive error. Slit lamp examination was normal and fundus examination did not reveal any in discrepancy. His final visual acuity was found to be better than $6 / 18$ in both eyes. Upon probing, patient revealed that there was vacancy in disability quota for which he required disability certificate with at least $40 \%$ disability.

\section{DISCUSSION}

Malingering and hysterical visual loss form part of functional visual disorders posing grave problem to the ophthalmologists particularly during assessment of disability. 
Malingering is the conscious expression of symptoms without demonstrable organic findings involving alteration of sensory motor functions.

Non-organic visual loss is not the diagnosis of exclusion but it requires tests to be done to establish the underlying cause. A number of causes may be there like psychiatric illnesses, attention deficit hyperactivity syndrome, somatoform disorders, learning disorders or conflicts at home. In paediatric as well as adult, eye OPD prevalence of non-organic vision loss is $1-5 \%$. Mean age of presentation in children is 11- 13 years and in adults it is 40 years. Females are affected more and $60-80 \%$ are bilateral. ${ }^{1}$ Somer A et al. reported that among children presenting with diminution of vision, $50 \%$ were with organic vision loss and $50 \%$ were with non-organic vision loss and in latter group girls outnumbered and mean age was 11 years. $^{2}$

It is easy to label a patient with non-organic vision loss and it can lead to dangerous consequences if patient is suffering from some organic disease like intra cranial space occupying lesion.

It is difficult to differentiate since both form part of nonorganic eye diseases. However, there are certain points which help to distinguish between the two entities. Malingerers usually exaggerate their symptoms however hysterics have la belle indifference. Hysterics are usually cooperative, but malingerers are usually irritable and non-cooperative. Moreover, malingering involves secondary gain but hysterics are concerned only with attention. In malingering, there is evidence of intentional false symptoms for personal gain, whereas in functional disorders, there is evidence of primary and secondary gain. In primary gain, emotional stimulation converts to physical symptoms whereas in secondary gain outer benefits like discharge from responsibilities is seen. ${ }^{3}$

Ocular Munchausen's syndrome also requires mention which is the deliberate deception by the patient involving fabricated medical history, self-inflicted abnormalities, and self-mutilation. Usually patient presents with pharmacological mydriasis, corneal ulcer, subconjunctival haemorrhage, conjunctivitis, and voluntary nystagmus. ${ }^{4}$

\section{Evaluation of Patient}

Meticulous history of patient is very important to reach the diagnosis of malingering which is in fact a diagnosis of exclusion. If the findings do not match the symptoms and history, there is medico legal dispute or secondary gain. Then, high index of suspicion for malingering should be kept. Young adults or adolescents facing stress at school or home and few people coming for certification of visual loss are affected. They can present with-

- Visual loss (Binocular or monocular)

- Diplopia (Monocular or binocular)

- Voluntary nystagmus.

- Altered lacrimation.

- Blood mixed tears.

- $\quad$ Ptosis and blepharospasm.

Examination of pupils particularly light reflex is the most important test for unilateral or asymmetrical visual loss. If it is normal, then it is unlikely that cause is organic barring cortical visual loss. ${ }^{5}$

\section{Total Binocular Blindness}

Total binocular blindness is usually rare and is found in hysterical patients. A malingerer consciously bumps into objects while hysterical avoids objects and truly blind moves cautiously and bumps into objects naturally.

\section{Pupillary Examination}

If direct and consensual pupillary response is intact, it denotes anterior visual pathway is disease free and at least perception of light and projection of rays is present.

\section{Menace Reflex}

There is blinking to visual threat. If blinking is present to the visual threat, it is unlikely that the person is blind.

\section{Psychogalvanic Test}

In strong and sudden illumination reflex, tearing cannot be suppressed.

\section{Signature Test}

If a person is truly blind, he doesn't have difficulty in signing but a malingerer tries to sign with illegibility. Looking at outstretched hands and touching index fingers is based on proprioception and not on visual acuity.

\section{Optokinetic Nystagmus}

A person with normal visual acuity cannot suppress optokinetic nystagmus. In a person claiming visual acuity worse than hand movement close to face (HMCF) or bilaterally blind eliciting optokinetic nystagmus establishes visual acuity at least $3 / 60$. In a bilaterally blind person, test is done with both eyes open and in unilateral blind person, test is started with both eyes open and then during the test, normal eye is occluded. If nystagmus is there, functional visual loss is proven.

\section{Tests for Proprioception}

Proprioception remains intact in a person with organic vision loss. Finger to finger or finger to nose test is done. Patient is asked to touch tips of middle finger of both hands or tip of nose with middle finger. A person with NOVL will not be able to touch finger tips or tip of nose.

\section{Visual Field Analysis}

Normal orientation of physiological visual field (VF) is funnel shaped i.e. when target is moved away from the subject, $V F$ expands. If $\mathrm{VF}$ analysis is done by confrontation method at one meter and then at 2, 3 and 4 meters and if there is no expansion of VF of the patient, NOVL is proven.

\section{Visual Evoked Response (VER)}

VER detects integrity of visual pathway. If VER is normal, functional visual loss is suggestive. 


\section{Total Mono Ocular Blindness}

It is more common than binocular blindness in malingerers. Any of the following tests or combination of these tests can be used to detect with uninvolved eye occluded.

\section{Diplopia Test}

After occluding involved eye, a prism of high power is placed in front of normal eye in such a way that its apex bisects the pupil. The patient will complain of uniocular diplopia. Then involved eye is uncovered and entire prism is placed in front of good eye producing binocular diplopia. If subject still reports diplopia, functional blindness is proven. If patient does not complain of diplopia, the cause of blindness is pathological.

\section{Fixation Test}

Before normal eye of the subject, a high diopter base out prism (Image 2) is placed which causes shifting of normal eye with refixation movement of another eye. In truly blind eye, there is no refixation movement.

\section{Vertical Bar Test}

A vertical bar is kept 5 inches away from the nose between the eyes and subject is instructed to read at near. Due to binocular vision, a normal person can read across the bar without interruption. However, if one eye is blind, person will pause to shift the fixation.

\section{Fogging Test}

Both eyes are kept open in trial frame and patient starts reading the chart. More plus lenses (Figure 1) are added progressively to the good eye while patient keeps on reading. Final line read by the patient is the visual acuity of the suspected eye.

\section{Crossed Cylinder Technique}

Two strong cylindrical lenses of equal power of plus and minus are placed in front of normal eye at same axis and patient is asked to read and in between, one lens is rotated at 45 degrees. If patient goes on reading, malingering is proven.

\section{Colour Test}

Patient wears red-green glasses in such a way that red is in front of affected eye. Eye behind red glass sees letters written in red. If person reads entire line without hindrance suspected eye is used.

Binocular vision loss testing involves bottom up strategy where first $6 / 5$ line is read then $6 / 6,6 / 9$ and so on. Patient is labelled with visual acuity which is better. Other strategy described is distance doubling where visual acuity is tested by varying the distance. If distance is reduced, visual acuity of the patient should improve, if not improving, it means patient is telling lie.6,7
Conditions misdiagnosed as functional visual loss-

- Keratoconus: Can be excluded by keratometry.

- Amblyopia: Usually associated with strabismus and anisometropia.

- Early Stargardt's disease: Macular examination and Fundus fluorescein angiography (FFA) can diagnose.

- Retinitis pigmentosa sine pigmenti: Electro retinography (ERG) is helpful in diagnosing this entity.

- Central serous chorioretinopathy: Fundus examination and FFA.

- $\quad$ Cone dystrophy: ERG is diagnostic.

\section{Treatment of Functional Visual Loss}

In functional visual loss and malingering, confrontation is rarely productive. So, it should be dealt with utmost care. Reassurance in addition to psychiatric consultation plays vital role in treating this entity. Eye drops, orthoptic exercises or glasses should be avoided as these draw attention towards the eyes and undermine the importance of assurance.2,8 Also meticulous care should be kept while examining patients who have been referred by the disability board and guidelines of Ministry of Social Justice Government of India should be adhered. ${ }^{9}$

\begin{tabular}{|c|c|c|c|c|c|}
\hline & 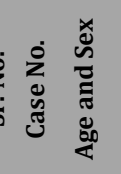 & 泀 & 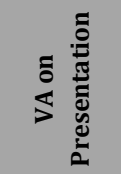 & 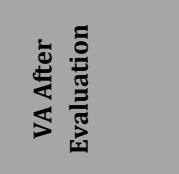 & 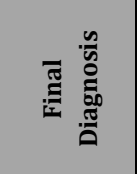 \\
\hline 1 & $\begin{array}{c}\text { Case } \\
1 \text { years } \\
\text { FA }\end{array}$ & $\begin{array}{l}\text { Decreased vision, } \\
\text { visual hallucinations, } \\
\text { VF impairment, } \\
\text { Depression }\end{array}$ & $6 / 240 \mathrm{U}$ & $6 / 24 \mathrm{OU}$ & $\begin{array}{c}\text { Primary } \\
\text { open angle } \\
\text { glaucoma }\end{array}$ \\
\hline 2 & $\underset{2}{\text { Case }} \begin{array}{c}70 \\
\text { years } \\
\text { MA }\end{array}$ & $\begin{array}{l}\text { Decreased vision, } \\
\text { altered } \\
\text { behaviour }\end{array}$ & $\mathrm{PL}+$ ve OU & $\mathrm{PL}+\mathrm{ve} \mathrm{OU}$ & $\begin{array}{c}\text { Glioblastoma } \\
\text { of brain }\end{array}$ \\
\hline 3 & $\underset{3}{\text { Case }} \begin{array}{c}26 \\
\text { years }\end{array}$ & Complete loss of vision & PL -ve OU & $6 / 6$ OU & $\begin{array}{l}\text { Functional } \\
\text { visual loss }\end{array}$ \\
\hline 4 & Case $\begin{array}{c}64 \\
4 \text { years } \\
\text { MA }\end{array}$ & $\begin{array}{l}\text { Decreased vision, } \\
\text { Required disability } \\
\text { certificate }\end{array}$ & $\begin{array}{c}\text { PL +ve } \\
\text { OD } \\
6 / 24 \text { OS }\end{array}$ & $>6 / 18$ OU & Malingering \\
\hline & $\underset{5}{\text { Case }} \stackrel{35}{\text { years }}$ & $\begin{array}{l}\text { Decreased vision, } \\
\text { Phthisis bulbi left eye, } \\
\text { Required disability } \\
\text { certificate }\end{array}$ & $\begin{array}{l}\mathrm{PL}-\mathrm{ve} \mathrm{OD} \\
6 / 24 \mathrm{OS}\end{array}$ & $\begin{array}{l}\text { PL -ve OD } \\
>\quad 6 / 18 \text { OS }\end{array}$ & Malingering \\
\hline 6 & $\begin{array}{c}\text { Case } \\
6 \begin{array}{c}20 \\
\text { years } \\
\text { MA }\end{array}\end{array}$ & $\begin{array}{c}\text { Decreased vision, } \\
\text { Required disability } \\
\text { certificate }\end{array}$ & $\begin{array}{l}6 / 60 \text { OD } \\
6 / 24 \text { OS }\end{array}$ & $>\quad 6 / 18 \mathrm{OU}$ & Malingering \\
\hline \multicolumn{6}{|c|}{ Table 1. Summary of Patients } \\
\hline
\end{tabular}

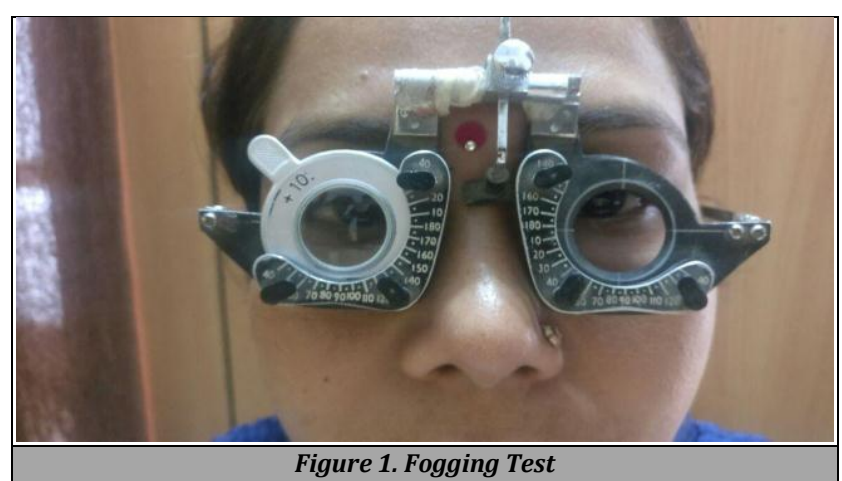




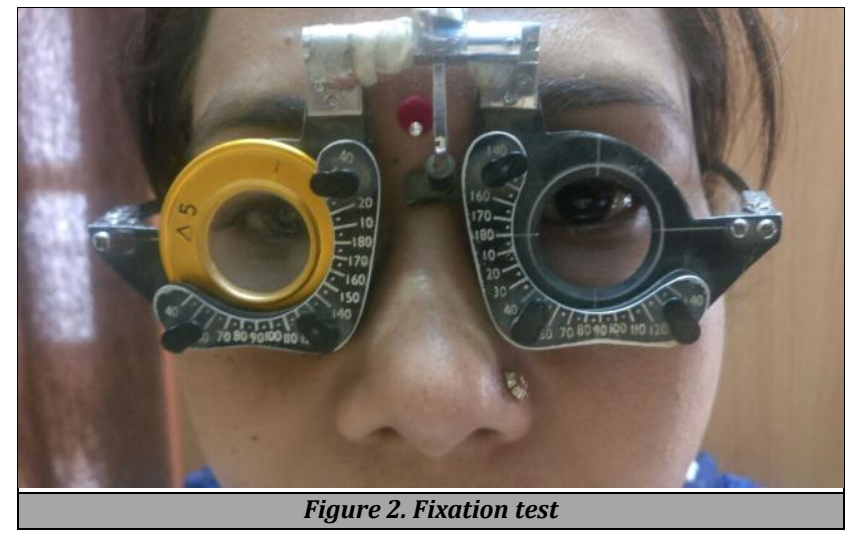

CONCLUSIONS

In modern day practice, an ophthalmologist should have enough knowledge of malingering which ranges from conversion reaction to Munchausen's syndrome or denial of pathology. Malingerer either feigns some disorder due to some gain or denies existence of pathology due to the fear of rejection. There should not be any hesitation to take the help of other disciplines or to admit the patient and examine him thoroughly especially when needed for medico legal or benefit cause. Examiner should use the method which is simplest and fastest and with which examiner is more conversant.

Financial or other competing interests: None.

Disclosure forms provided by the authors are available with the full text of this article at jemds.com.

\section{REFERENCES}

[1] Kini A, Ajjeya MT, Sudhakar P. Non organic vision loss. European Ophthalmic Review 2020;14(1):26-33.

[2] Somers A, Casteels K, Van Roie E, et al. Non-organic visual loss in children: prospective and retrospective analysis of associated psychosocial problems and stress factors. Acta Ophthalmologica 2016;94(5):e312-6.

[3] Barnum R. Problems with diagnosing conversion disorder in response to variable and unusual symptoms. Adolesc Health Med Ther 2014;5:67-71.

[4] Fish RH. Functional visual disorders. In: Kline LB, Bajandas FJ, eds. Neuro- Ophthalmology Review Manual. Revised $5^{\text {th }}$ edn. NJ, USA: SLACK Incorporated 2004: p. 209-220.

[5] Ali Ihsan I. Tests for malingering in Ophthalmology. Int J Ophthalmol 2013;6(5):708-17.

[6] Pula J. Functional vision loss. Curr Opin Ophthalmol 2012;23(6):460-5.

[7] Bruce BB, Newman NJ. Functional visual loss. Neurol Clin 2010;28(3):789-802.

[8] Venkatramani D. Functional visual loss. In: Khurana AK, edr. Neuro Ophthalmology. $1^{\text {st }}$ edn. New Delhi: CBS Publications 2014: p. 199-204.

[9] The Gazette of India. No-61, Guidelines for RPWD Act 2016. New Delhi: Ministry of Social Justice and Empowerment, Department of Empowerment of Persons with Disabilities. Jan 05, 2018. 